\title{
La inmigración marroquí en la literatura española actual
}

\section{The Moroccan immigration in current spanish literature}

\begin{abstract}
Mohammed Ouahib ${ }^{\mathbf{1}_{\odot}}{ }^{1}$ Universidad Sidi Mohamed Ben Abdellah. Facultad de Letras y Ciencias Humanas Dhar el Mehraz. Fez, Marruecos.*Autor de correspondencia: mohammed.ouahib@ gmail.com.
\end{abstract}

Ouahib, M. (2021). La inmigración marroquí en la literatura española actual. Investigaciones y Estudios - UNA, 12 (2), 28-38. https://doi.org/10.47133/IEUNA2123b

Resumen. El presente artículo tiene como objetivo reflexionar sobre la temática de la inmigración en la literatura española actual, producida por la intensa llegada a España de emigrantes tanto legales como ilegales a partir de los años noventa, procedentes de muchos rincones del mundo. El fenómeno de la emigración marroquí a España no ha dejado impasible a algunos escritores españoles cuya reacción ha consistido en intentar cristalizar los dramas y las muertes trágicas ocurridas en el Estrecho de Gibraltar en sus textos. Por esta misma razón, nuestro trabajo pretende ser una cierta -y no exhaustiva- aproximación a esta problemática cuya realidad se manifiesta en todos los campos de la sociedad española, sobre todo, en su literatura, ya que esta es siempre un reflejo de la sociedad en la que se desarrolla.

Palabras clave. inmigración, emigración, literatura, España, Marruecos.

\begin{abstract}
The aim of this article is to reflect on the theme of immigration in current Spanish literature, produced by the intense arrival in Spain of both legal and illegal emigrants since the 1990s, coming from many corners of the world. The phenomenon of Moroccan emigration to Spain has not left unmoved to some Spanish writers whose reaction consists in trying to crystallize the dramas and tragic deaths occurred in the Strait of Gibraltar in their texts. For this precise reason, our work intends to be a certain -and not exhaustiveapproach to this problematic whose reality is manifested in all fields of Spanish society, above all, in its literature, since this is always a reflection of the society in which it develops.
\end{abstract}

Keywords. immigration, emigration, literature, Spain, Morocco.

\section{INTRODUCCIÓN}

Hoy en día, la actualidad española está marcada, entre otros retos fundamentales, por la masiva llegada de los flujos migratorios, principalmente, desde el Norte de África hacia España y, por consiguiente, al resto de Europa. Tales flujos de 
población africana no dejan de ser una fuente de gran interés tanto para la política internacional y la prensa como para la sociología y la literatura. En este artículo, nos interesan los aspectos específicos de una literatura cuyos propósitos residen en tratar de reflejar la tragedia humana a través de la ficción del impactante drama que ocurre casi cada día a orillas del Estrecho de Gibraltar.

Al principio, el fenómeno de la emigración hacia España, particularmente por su dimensión clandestina y dramática, venía llamando la atención de muchos estudiosos y analistas pertenecientes a distintas disciplinas, tales como la sociología, demografía, economía, política, entre otras. En cambio, son escasos los estudios y trabajos realizados sobre la producción artística de temática migratoria, tema considerado por la mayoría como género menor. Pero, a consecuencia del creciente número de emigrantes que intentan llegar al territorio español procedentes de los países pobres, algunos escritores se vieron obligados a reflexionar y transmitir lo que sucede a diario y ante sus ojos en el Estrecho de Gibraltar.

\section{Inmigración marroquí en la literatura}

española actual. Es importante empezar con una frase significativa de Ortega y Gasset que dijo en una ocasión que "el tema de la novela es siempre la actualidad" (Zovko, 2009, p. 163-172), por lo cual, los escritores mundialmente conocidos intentan reflejar los problemas y las preocupaciones de la época en la que viven, y este es el papel que desea desempeñar la literatura española actual ambientada en torno a la emigración clandestina. Un artículo publicado a este respecto por el periódico $E l$ Público señala que "El cayuco llega a la narrativa: la narrativa española actual retrata la realidad de los inmigrantes" (Corroto, 2007), de modo que los inmigrantes han entrado como personajes de ficción en la literatura española actual.

A partir de los años 90, algunos escritores, tanto españoles como marroquíes, empezaron a reaccionar ante los naufragios producidos en el Mediterráneo, con el fin de recrear en sus obras esta triste realidad produciendo una nueva literatura situada entre dos orillas cuyo espacio novelesco común es el miserable y dolorido Estrecho. Una literatura que recibe varias nominaciones, tales como "literatura de la emigración", "literatura de la supervivencia", "literatura de pateras", "literatura de la frontera" o "ficción del Estrecho", siendo el cruce de la frontera, el Estrecho, la sobrevivencia y la patera el eje fundamental de esta literatura en la narración de vidas y vicisitudes de personas que se juegan la vida intentando llegar desde países del Sur a la otra ribera del Norte.

La literatura sobre la emigración es un tema todavía bastante marginal en España. La falta de estudios críticos y de otras obras sobre el fenómeno migratorio se debe, probablemente, al hecho de que la emigración es un tema reciente en el país ibérico. Esto lo dejan entrever estas palabras de Irene Andrés Suárez, "hasta ahora, sólo se han estudiado de una manera pormenorizada las obras del exilio, y todas aquellas que tratan de otros aspectos de la emigración apenas se han investigado" (AndrésSuárez, 2002, p. 19). Hay que señalar que no es solo en España donde no se ha atendido este campo de investigación, sino también en otros países europeos tradicionales de emigración como lo son Francia, Alemania, Holanda o Reino Unido. Pero, afortunadamente, hay "indicios de que un día se prestará atención al fenómeno literario de la emigración”. (Duroux, 2002, p. 577-596).

Hay una notoria falta de una gran novela de la 
inmigración en la España de hoy en día, y concretamente una producción literaria de relieve, puesto que la mayor parte de las publicaciones acerca del tema son solo ensayos o libros socioeconómicos, e incluso, obras literarias, escritas generalmente desde una perspectiva periodística, documental o testimonial, carentes de valor estético:

La mayoría de los autores que escriben sobre el tema de la inmigración son poco conocidos, a menudo trabajan en el periodismo, o tienen alguna relación particular con la inmigración por razones políticas o biográficas. Los escritores españoles que se ocupan seriamente del tema lo hacen sobre todo por un compromiso humanitario y por solidaridad, pero, desde el punto de vista estético, los resultados suelen decepcionar...Para la mayoría de estos autores, la inmigración es un tema, un problema, un motivo o un pretexto, pero no una experiencia profunda, no una vivencia personal. (Kunz, 2002, p. 135).

En efecto, hay que reconocer la notable ausencia de los inmigrantes en la literatura española actual, que contrasta, según explica Marco Kunz, con su importante protagonismo y fuerte presencia en los debates políticos y en los medios de comunicación: "Se constata una casi total ausencia de los inmigrantes en la literatura española contemporánea, ausencia que se opone diametralmente a su presencia en la prensa diaria y el debate político" (Kunz, 2002, p. 133).

Es importante señalar que aproximadamente a partir del año 2000 hay una literatura marroquí en español y en catalán escrita por emigrantes de segunda generación como Najat El Hachmi, Laila Karrocuh y Said El Kadaoui Moussaoui, que se debaten entre el afianzamiento de los valores tradicionales y la apertura a Occidente, pero que no tratan el problema migratorio en sí mismo.

Por esta razón, no podemos hablar de una literatura escrita por los propios inmigrantes sobre el fenómeno migratorio en España, dado que este proceso surgido en España dicho país es novedoso, que arrancó aproximadamente a partir de los años noventa. Tal vez en el futuro, los hijos de los inmigrantes puedan escribir su propia historia $\mathrm{y}$ sentirse atraídos por las desgracias y dramas de la inmigración en el Estrecho. De este modo, probablemente podemos toparnos en tiempos venideros con textos literarios objetivos y fieles a su realidad, en contraste con los autores españoles que retratan una experiencia ajena a ellos y un fenómeno que no han experimentado desde cerca.

Podemos decir que la producción literaria referida al fenómeno migratorio se encaja en el marco de la literatura española de tema marroquí. En este sentido, compartimos la afirmación de Mohamed Abrighach que sostiene que la literatura sobre la emigración marroquí: “...Puede considerarse como una continuación de la literatura morisca y de los romances fronterizos de la Edad Media y del Renacimiento, porque vuelve a tratar supuestas luchas/convivencias entre moros $\mathrm{y}$ cristianos, en alarde de una cultura mestiza y multicultural". (Abrighach, 2006, p. 286).

Este tipo de literatura destaca por su fuerte discurso de denuncia a la tragedia de la emigración clandestina, de igual modo manifiesta un verdadero malestar contra los países europeos. Por lo tanto, versa, principalmente, sobre la otredad en tanto que narración ideológica, sociológica, antropológica y hasta psicológica del otro. Asimismo, se destaca por la presencia de una variedad de géneros, de diferentes voces narrativas, de doble lenguaje e 
intertextualidad.

A este respecto, es importante señalar que esta literatura es considerada una literatura africanizada, porque la mayoría de sus textos literarios, teatrales y artísticos se centran en el emigrante marroquí y africano sin prestar bastante atención al emigrante procedente de otros países, por lo que se tiende a la africanización del imaginario narrativo sobre la emigración, concretamente la marroquí. (Kunz, 2002, p. 133) En efecto, esta tendencia africanista se justifica por el abundante número de emigrantes oriundos de países con una cultura, religión y lengua totalmente diferentes a la española en particular y a la europea en general.

La masiva llegada de pateras a las costas españolas y la travesía de emigrantes en las mismas convierten la narrativa sobre la emigración en una especie de literatura de pateras (Kunz, 2002, p. 133). En ella se acentúa la poética de la solidaridad, humanización y sentimentalismo al narrar las tribulaciones de los emigrantes, sus naufragios en el Estrecho y las dramáticas muertes de los harraga en el fondo del mar. El término "harraga" viene del árabe que se refiere a los emigrantes ilegales que queman sus documentos de identidad con la finalidad de dificultar su repatriación. Es decir, la persona que atraviesa el Estrecho ilegalmente, esta palabra es popular en el lenguaje vinculado al fenómeno migratorio. Las tragedias interminables y los cadáveres en las costas tanto españolas como marroquíes, han llevado a la producción de todo un tipo de relatos marítimos, similares a la gran literatura del mar, desarrollada por ilustres escritores occidentales tales como Robert Louis Stevenson, Jules Verne, Herman Melville, etc. (Séka, 2017, p. 260-281).

Desde siempre, la literatura intenta reproducir la realidad del ser humano en sus vivencias $\mathrm{y}$ complejidades, definidas desde diferentes puntos de vista como expresión humana, manifestación cultural y posición ideológica. En este contexto, los escritores que han tocado el tema migratorio han procurado transmitir sus ideas acerca de lo que pasa en su entorno, y se han convertido de esta forma en el vocero de una sociedad afectada por la emigración clandestina, las muertes casi diarias en el Estrecho, así como las condiciones infrahumanas en las que viven los emigrantes, es decir la dura realidad a la que se enfrentan a su llegada a España y los mayores problemas de integración que padecen. "La literatura por su carácter simbólico puede contribuir a un conocimiento más profundo del tema y a la iluminación de aspectos oscuros o invisibles". (Andrés-Suárez, 2004, p. 16).

Obviamente, a través de este tipo de literatura conocemos de cerca las historias de los emigrantes, sus sueños, sus sufrimientos y angustias, también conocemos sus países de origen, sus aventuras, sus intenciones, sus experiencias, sus nombres, sus pensamientos y sus emociones; cosas que desconocemos mediante los medios de comunicación que se basan, generalmente, en las cifras y la transmisión superficial de noticias imprecisas e incompletas sobre los mismos. “...Por esto puede decirse que la literatura, cualesquiera fueren las escuelas en cuyo nombre se declare, es absoluta y categóricamente realista: ella es la realidad, o sea, el resplandor mismo de lo real". (Barthes, 1986, p. 125).

Cabe señalar que la emigración es un tema que está presente en todos los géneros literarios desde cuentos, relatos, ensayos, obras teatrales hasta novelas. A continuación, citamos algunas obras españolas escritas sobre esta temática por escritores, 
por lo general, poco conocidos, salvo algunas excepciones, en su mayoría vinculados al periodismo: La aventura de Said de Josep Lorman (1996), Las voces del Estrecho de Andrés Sorel (2000), Fátima de los naufragios de Lourdes Ortiz (1998), La cazadora de Encarna Cabello (1995), Harraga de Antonio Lozano (2002), Donde mueren los ríos de Antonio Lozano (2007), La patera y otros relatos de José Juan Cano Vera (1998), Tarifa. La venta del alemán de Eduardo Iglesias (2004), Por la vía de Tarifa de Nieves García Benito (1999), Europa se hunde de Miguel Ángel de Rus (2005), Ramito de hierbabuena de Gerardo Muñoz Lorente (2001), Aguas de cristal, costas de ébano de Adolfo Hernando Lafuente (1999), Yo, Mohamed. Historias de inmigrantes en un país de emigrantes de Rafael Torres (1995), Al calor del día de Miguel Naveros (2001), Gálvez en la frontera de Jorge Martínez Reverte (2008), ¿Dónde estás Ahmed? de Manuel Valls (2000), Monteluz de Manuel Pimentel (2002), Ahlán de Jerónimo López Mozo (1998), La mirada del hombre oscuro de Ignacio del Moral (2013), Nuestro amigo Mustafá de Juan Rey (2009), La Baraka y otros textos marruecos de Salvador López Becerra (2018).

Gran parte de las obras mencionadas tratan, comúnmente, por un lado, temas de identidad, mestizaje, racismo y naufragios; y por otro, la marginación y la delincuencia de extranjeros, además del mundo de la mafia y el tráfico de drogas y personas, del que el emigrante es tanto verdugo como víctima, señalando problemas relacionados con la sensación miedosa de la no pertenencia y de la no estabilidad del emigrante fuera de su patria y sus raíces.

Otro aspecto primordial de estas obras gira en torno a la compasión, mediante la narración del fenómeno migratorio con mucha angustia y drama, con la intención de conmover al lector en forma de solidaridad con los inmigrantes e identificación de los lectores con las miserables y horribles condiciones de los mismos:

¡Cómo gritar ante la indiferencia, indolencia, insensibilidad, frente a los tres mil muertos del Estrecho! No hay grito. No hay toalla para proteger a los ahogados, ni de la cámara hostil, ni de la mirada morbosa en los informativos. La libertad de indignarse, la compasión, parecen pérdidas en el laberinto obtuso de la carrera de imágenes. (García Benito, 1999, 77; Soler-Espiauba, 2004).

Asimismo, la mayor parte de dichas obras comparten ciertas características y peculiaridades, el primer componente de estos escritos gira en torno a las circunstancias de la existencia de los inmigrantes en busca de nuevas oportunidades, también los problemas a los que se enfrentan en el país de destino. El segundo componente se refiere a los espacios donde transcurren los hechos, ya que son lugares reconocibles y situados, en su mayoría, en el norte de Marruecos: Chauen, Tánger, Nador, Tetuán, etc. En cuanto al último elemento, se trata de un lenguaje muy fuertemente plagado de palabras de origen árabe, lo que nos ofrece un lenguaje híbrido, mixto y heterogéneo.

En cuanto al aspecto formal, cabe señalar lo que se denomina "paterización de la literatura" tanto en el contexto español como en el marroquí; es decir, el predominio de la problemática de las pateras, destacando de una manera directa e inmediata la llegada de los inmigrantes ilegales y su paso por el Estrecho de Gibraltar, un espacio que se ha convertido lamentablemente en el tanatorio de los emigrantes.

Existen dos características principales que 
definen la literatura de tema migratorio, se trata de una poética realista y una estética de compasión; así como tres modalidades narrativas, en primer lugar, la mímesis o imitación de la realidad con base documental (realismo mimético); en segundo lugar, una mezcla entre vida y ficción (realismo simbiótico); por último, una modalidad caracterizada por el lirismo poético (realismo poético) (Abrighach, 2006, p. 28).

Las obras literarias de inmigración se caracterizan por un aspecto autobiográfico $\mathrm{y}$ comprometido, dado que la mayoría de los autores escriben manteniendo una relación estrecha con el fenómeno migratorio. $\mathrm{Su}$ principal propósito consiste en criticar y denunciar las políticas injustas y el tratamiento que sufren los inmigrantes ilegales, de modo que su propia experiencia influye en sus escritos que reflejan una verdadera obsesión por meterse en la piel del emigrante, víctima de un doble sufrimiento en las dos sociedades de origen y de destino.

El enfoque metodológico de nuestro trabajo se sustenta sobre el eclecticismo como método que no se apoya en una determinada teoría. No obstante, se inclina hacia la literatura comparada con la finalidad de obtener información complementaria de un tema, teniendo como fuente el tema de la otredad y la relación entre el Norte y el Sur, dado que la temática migratoria gira en torno al discurso sobre el otro.

Nuestra investigación sirve como un ámbito para poner de manifiesto una problemática, que es la inmigración clandestina, que afecta a la comunidad internacional, sobre todo a los dos países vecinos: Marruecos y España. Además, subrayamos la falta de trabajos académicos y científicos realizados al respecto, que permite, a veces, como en nuestro caso, entender el aspecto humano y trágico de la inmigración irregular.

Nuestro trabajo resalta que el inmigrante no es un sujeto que se acoge calurosamente en el país de destino, la sociedad española en particular, y la Europa en general, en su conjunto, no es muy amable con los inmigrantes marroquíes, aunque son los que mantienen, en gran medida, la economía sumergida. Lo asombroso es que España fue hasta fechas recientes país emisor de emigrantes, y ha vivo esta experiencia, pero no es muy amable con los inmigrantes. Y hay otra reflexión que nunca aparece, que es ¿cuánto preocupa al país de origen, a sus gobernantes, el sufrimiento de sus emigrantes? Este es un problema polifacético que se ha ido complicando mucho con la globalización de la información.

\section{CONCLUSIÓN}

A modo de conclusión, la característica específica de la actual literatura española de emigración consiste en el hecho de producir y reunir un mosaico de géneros literarios, ya que unas veces se trata de una literatura que mezcla la ficción y el reportaje, otras veces nos encontramos con obras de ficción y ensayo, que acaban siendo relatos y textos testimoniales, documentales o periodísticos. Prueba de ello, es el uso de lugares, hechos y personajes tomados de la realidad, esto se debe principalmente al tratamiento de los problemas concretos y reales de los inmigrantes clandestinos.

Ciertamente, gran parte de obras sobre esta temática tiende a utilizar personajes que parecen de carne y hueso y no plenamente ficticios, porque los escritores retratan hechos que ven con sus propios 
ojos y sobre un fenómeno humanitario que afecta a todo su entorno y que representa un verdadero desafío a la humanidad.

Otro de los rasgos principales de esta literatura consiste en su papel reivindicativo, militante, denunciador e ideológico a favor de personas que son ignoradas y castigadas en nuestros días, con el objetivo de moralizar y hacer hincapié en la falta de interés del mundo acerca de los inmigrantes, en la denuncia y crítica de su situación social, en la necesidad de la dignidad de los inmigrantes frente al silencio de las sociedades occidentales. Ante esta tremenda situación, la pluma de estos escritores pone de relieve la idea de crisis y alarma sobre los problemas derivados de los movimientos migratorios y se centra en la problemática de esta minoría a través de la literatura entendida como una fuerza para crear mundos no sometidos y para expresar una condición de vida.

Por otra parte, cabe resaltar que este tipo de literatura pone de manifiesto que el fenómeno migratorio no solo concierne al emigrante sino también al país de origen como al de destino, señalando de esta forma las situaciones tan complejas a las que se enfrenta el emigrante en ambos países.

Finalmente, no podemos dejar de señalar que, a lo largo de la historia siempre ha habido movimientos de individuos que se desplazaban de unos lugares a otros tanto en busca de mejores oportunidades económicas como la de adquirir conocimientos y saberes sobre otros pueblos. La novedad de la actual emigración y su posterior aparición y cristalización en los textos literarios es su carácter clandestino y trágico, a diferencia de la clásica y tradicional actividad humana de moverse de un país a otro como un derecho humano.
Declaración de interés. Los autores declaran

no tener conflicto de intereses.

\section{REFERENCIAS BIBLIOGRÁFICAS}

Abrighach, M. (2006). La inmigración marroquí y subsahariana en la narrativa española actual, (Ética, estética e interculturalismo). Facultad de Letras y Ciencias Humanas/ORMES. Agadir. Marruecos.

Andrés Suárez, I. (2002a). Mitos e imágenes de la migración en la literatura española contemporánea. En Actas del XIV Congreso de la Asociación Internacional de Hispanistas, 16 al 24 de julio, p.p. 53-63. New York. Universidad de Neuchâtel.

Andrés-Suárez, I. (Ed.). (2002b). Introducción en la inmigración en la literatura española contemporánea. En Migración y literatura en el mundo hispánico, Actas del Coloquio Internacional. Madrid. Verbum. Universidad de Neuchâtel.

Andrés Suárez, I. (2004). Migración y literatura en el mundo hispánico, Actas del Coloquio Internacional. Madrid. Universidad de Neuchâtel. Verbum, p. 16.

Barthes, R. (1986). El placer del texto, seguido por Lección Inaugural. México. Siglo XXI Editores.

Cabello, E. (1995). La cazadora: novela. Vol. 4. Ciudad de Melilla. Consejería de Cultura, 109 p.

Corroto, P. (2007). El cayuco llega a la narrativa: la narrativa española actual retrata la realidad de los inmigrantes. El Público. https://www.publico.es/culturas/libros/cayucollega-narrativa.html

Duroux, R. (2002). La emigración a Francia (segunda mitad del siglo XX). Unas reflexiones sobre retornos y reintegraciones". Hispania, 62, (211), 577-595.

García Benito, N. (1999). Por la vía de Tarifa. Madrid. Calambur.

Iglesias, E. (2004). Tarifa: la venta del alemán. El tercer nombre, Editorial.

Del Moral Ituarte, I. (2013). La mirada del hombre oscuro. Madrid. Ediciones Eride.

Kunz, M. (2002). La inmigración en la literatura española contemporánea: un panorama crítico. En La inmigración en la literatura española contemporánea. Madrid. Verbum.

Lafuente, A. H. (1999). Aguas de cristal, costas de ébano. Cálamo.

López Becerra, S. (2018). La Baraka y otros textos marruecos. Málaga. Centro cultural de la Generación del 27.

López Mozo, J. (1998). Ahlán. Alicante. Biblioteca Virtual Miguel de Cervantes.

Lorman, J. (1996). La aventura del Said. Ediciones SM. Lozano, A. (2002). Harraga. Granada. Zoela: Ediciones. Muñoz Lorente, G. (2001). Ramito de hierbabuena. 
Barcelona. Plaza \& Janés.

Naveros, M. (2001). Al calor del día. Madrid. Alfaguara.

Ortiz, L. (1998). Fátima de los naufragios. Relatos de tierra y mar. Barcelona. Planeta.

Pimentel Siles, M. (2002). Monteluz. Barcelona. Planeta.

Reverte, J. M. (2008). Gálvez en la frontera. Madrid. Booket.

Rey Fuentes, J. (2009). Nuestro amigo Mustafá. Editorial: Algaida.

Rus, M. Á. de. (2005). Europa de hunde. Madrid. (2 ed.). S.L. Ediciones Irreverentes.

Séka, C. E. (2017). Exode et immigration dans: Las voces del Estrecho. Universidad de Granada, España. Impossibilia, Revista Internacional de Estudios Literarios, 14, 260-281.
Soler-Espiauba, D. (coord.). (2004). Literatura y pateras. Madrid. Universidad Internacional de Andalucía/Akal.

Sorel, A. (2000). Las voces del Estrecho. Barcelona. Muchnik.

Torres, R. (1995). Yo, Mohamed: Historias de inmigrantes en un país de emigrantes. Madrid. Temas de Hoy.

Valls, M. (2000). ¿Dónde estás, Ahmed? Madrid. Editorial Anaya.

Zovko, M. (2009). La imagen del inmigrante en la novela española actual. Altre Modernità, Revista di studi letterari e culturali, 2, 163-172. 